\title{
Evaluation of prognostic and predictive value of microtubule associated protein tau in two independent cohorts
}

\author{
Maria T Baquero ${ }^{1}$, Karen Lostritto ${ }^{2}$, Mark D Gustavson ${ }^{3}$, Kimberly A Bassi ${ }^{4}$, Franck Appia ${ }^{4}$, Robert L Camp ${ }^{1}$, \\ Annette M Molinaro ${ }^{5}$, Lyndsay $\mathrm{N} \mathrm{Harris}^{6}$ and David L Rimm ${ }^{1^{*}}$
}

\begin{abstract}
Introduction: Microtubule associated proteins (MAPs) endogenously regulate microtubule stabilization and have been reported as prognostic and predictive markers for taxane response. The microtubule stabilizer, MAP-tau, has shown conflicting results. We quantitatively assessed MAP-tau expression in two independent breast cancer cohorts to determine prognostic and predictive value of this biomarker.

Methods: MAP-tau expression was evaluated in the retrospective Yale University breast cancer cohort $(n=651)$ using tissue microarrays and also in the TAX 307 cohort, a clinical trial randomized for TAC versus FAC chemotherapy $(n=140)$, using conventional whole tissue sections. Expression was measured using the AQUA method for quantitative immunofluorescence. Scores were correlated with clinicopathologic variables, survival, and response to therapy.

Results: Assessment of the Yale cohort using Cox univariate analysis indicated an improved overall survival (OS) in tumors with a positive correlation between high MAP-tau expression and overall survival (OS) $(\mathrm{HR}=0.691,95 \% \mathrm{Cl}=$ 0.489-0.974; $P=0.004$ ). Kaplan Meier analysis showed 10-year survival for $65 \%$ of patients with high MAP-tau expression compared to 52\% with low expression $(P=.006)$. In TAX 307, high expression was associated with significantly longer median time to tumor progression (TTP) regardless of treatment arm (33.0 versus 23.4 months, $P=0.010)$ with mean TTP of 31.2 months. Response rates did not differ by MAP-tau expression $(P=0.518)$ or by treatment arm $(P=0.584)$.

Conclusions: Quantitative measurement of MAP-tau expression has prognostic value in both cohorts, with high expression associated with longer TTP and OS. Differences by treatment arm or response rate in low versus high MAP-tau groups were not observed, indicating that MAP-tau is not associated with response to taxanes and is not a useful predictive marker for taxane-based chemotherapy.
\end{abstract}

Keywords: microtubule associated protein- tau (MAP-tau), metastatic breast cancer, taxanes, prognostic, predictive, quantitative analysis, immunohistochemistry

\section{Introduction}

Taxanes are microtubule stabilizing agents and potent cytotoxic compounds that have been recognized as highly effective chemotherapeutic agents [1,2]. However, varying degrees of benefit, with response rates ranging from $32 \%$ to $68 \%$ in the adjuvant and metastatic settings, suggest

\footnotetext{
*Correspondence: david.rimm@yale.edu

'Yale University School of Medicine, Department of Pathology, 310 Cedar St, New Haven, CT 06520, USA

Full list of author information is available at the end of the article
}

the critical need for a companion diagnostic to predict which patients are most likely to benefit from taxane therapy and which can be spared the cytotoxic effects of such therapy [3].

Taxanes induce mitotic arrest and tumor cell apoptosis through the hyper-stabilization of microtubules. Biomarkers that indicate the state of microtubule stability in the cell could be useful for predicting taxane response. Microtubule associated proteins (MAPs) are endogenous regulators of microtubule stability, functioning to promote or

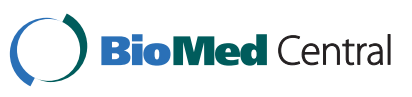


inhibit microtubule polymerization and determining subsequent cell cycle progression or mitotic arrest. These proteins may serve as potential candidates for a companion diagnostic.

MAP-tau (Tau) is a well characterized microtubule stabilizer that is responsible for the bundling, spacing, and assembly of microtubules [4-6]. MAP-tau may compete for taxane binding sites and/or may be involved in the cooperative binding of taxol to microtubules $[7,8]$. Initial reports evaluating MAP-tau as a predictive marker have been conflicting. Early studies measuring MAP-tau mRNA levels in the neoadjuvant setting found significantly lower levels in patients with pathologic complete response $[7,9]$ but no correlation with pathologic complete response was observed in patients from a subset of the GEPARTRIO trial [10]. Similarly, in a subset of the Hellenic Cooperative Oncology Group (HeCOG) trial, MAP-tau mRNA expression status was found to be nonpredictive of benefit from paclitaxel in the adjuvant setting [11]. When MAP-tau protein expression was evaluated, most often using traditional immunohistochemical methods, conflicting results were also found. Within the adjuvant setting, in the NSABP-B 28 randomized clinical trial, there was no prediction of benefit from paclitaxel but high MAP-tau expression was a positive prognostic marker for improved survival [12]. In advanced breast cancer patients, an early study of MAP-tau expression found no prediction of benefit from taxane therapy [13]. However, two additional studies of advanced breast cancer patients found high MAP-tau expression predictive for response to paclitaxel $[14,15]$ and a positive prognostic marker for improved overall survival [15].

The goal of this study was to clarify the prognostic and predictive value of MAP-tau. Protein expression for MAPtau was quantitatively assessed using two independent cohorts. Prognostic value was evaluated using a large Yale University retrospective cohort of untreated, primary breast cancer patients. Predictive value for MAP-tau was assessed using tumor tissue from TAX 307, a randomized clinical trial that examined patient response to the taxane, docetaxel, with docetaxel as the only variable. To date, no studies evaluating MAP-tau as a biomarker have assessed patient response using only taxane therapy as the randomized treatment variable. The TAX 307 trial randomized docetaxel-doxorubicin-cyclophosphamide (TAC) versus 5fluorouracil-doxorubicin-cyclophosphamide (FAC) as first-line chemotherapy for metastatic breast cancer. Patients were allowed to receive prior adjuvant endocrine therapy (tamoxifen) and/or chemotherapy but no prior taxanes were allowed. In this trial, inclusion of docetaxel resulted in an improved response rate $(P=0.02)$ but did not improve time to tumor progression (TTP) $(P=0.51)$ or overall survival $(P=0.93)$ compared with FAC alone [16].

\section{Materials and methods}

\section{Patient and cohort characteristics}

Formalin-fixed paraffin-embedded primary breast cancer tumors resected from 651 patients at Yale University/ New Haven hospital between 1962 and 1983 were obtained from the archives of the pathology department at Yale University (New Haven, CT, USA) and have been previously described in detail [17] (see Table S1 in Additional file 1). Specimens and associated clinical information were collected under informed consent under the ethics guidelines and approval of the Yale Human Investigation Committee under protocol \#8219 to DLR.

The second cohort, a prospectively collected, randomized phase III clinical trial, compared TAC versus FAC [16]. Patients were enrolled between 1 January, 1998 and 31 December, 1999, with a total of 489 patients randomized to receive either FAC $\left(75 / 50 / 500 \mathrm{mg} / \mathrm{m}^{2}\right)$ or TAC $\left(500 / 50 / 500 \mathrm{mg} / \mathrm{m}^{2}\right)$ as first-line chemotherapy for metastatic breast cancer. Prior adjuvant chemotherapy (but not a taxane and not $>240 \mathrm{mg} / \mathrm{m} 2$ doxorubicin) was allowed. A total of $39 \%$ of patients received prior adjuvant chemotherapy of whom $11 \%$ had received anthracyclines previously. Patients may have also received prior adjuvant hormonal therapy (described in more detail in Results).

Cycles were repeated every three weeks for six to eight cycles, depending on cumulative dose of prior doxorubicin treatment. Median patient age was 54 years with median follow-up time of 30 months, median disease-free survival of 27 months, and median number of cycles of TAC or FAC equal to six.

Baseline characteristics were well balanced and major negative prognostic factors were similar in both arms. Specimens and associated clinical information were collected under informed consent under the ethics guidelines and approval of the Dana Farber Human Investigation Committee and Yale Human Investigation Committee under protocol \# 0804003757 to LH. Tumor blocks were available for 140 patients from this trial and represented 28.6\% of all clinical trial participants. The TAX 307 subgroup (TAX 307S) showed no differences in patient characteristics when FAC and TAC treatment randomization groups were compared (Table 1). In addition, no significant differences in clinical characteristics were observed between TAX 307S and the original TAX 307 cohort indicating TAX $307 \mathrm{~S}$ to be a representative subset.

\section{Tissue microarrays and whole tissue slides}

Tissue microarrays (TMAs) were constructed as previously described [17]. In brief, tissue specimens were prepared for microarray format by selecting representative breast tumor areas from 651 formalin-fixed, paraffin-embedded primary tumor blocks using hematoxylin and eosin stained whole-section slides. Breast core samples $0.6 \mathrm{~mm}$ in diameter were arrayed in a recipient 
Table 1 Clinicopathologic characteristics of TAX 3075 stratified by treatment (TAC vs.FAC)

\begin{tabular}{|c|c|c|c|}
\hline \multirow[b]{2}{*}{ Variable } & \multicolumn{2}{|c|}{ Treatment group } & \multirow[b]{2}{*}{$P^{*}$} \\
\hline & $\mathrm{FAC}^{1}(\mathrm{n}=54)$ & $\operatorname{TAC}^{2}(n=54)$ & \\
\hline \multicolumn{4}{|l|}{ Menopausal status } \\
\hline Premenopausal & $9(16.7)$ & $15(27.8)$ & 0.119 \\
\hline Postmenopausal & $36(66.7)$ & $28(51.9)$ & \\
\hline Other & $9(16.7)$ & $11(20.4)$ & \\
\hline \multicolumn{4}{|l|}{ Tumor size $(\mathrm{cm})$} \\
\hline$\leq 2$ & $9(16.7)$ & $15(27.8)$ & 0.216 \\
\hline $2-5$ & $29(53.7)$ & $27(50.0)$ & \\
\hline$\geq 5$ & $12(22.2)$ & $10(18.5)$ & \\
\hline Other & $4(7.4)$ & $2(3.7)$ & \\
\hline \multicolumn{4}{|l|}{ Nodal status } \\
\hline Negative for node metastasis & $16(29.6)$ & $17(31.5)$ & 0.874 \\
\hline Positive for node metastasis & $29(53.7)$ & $33(61.1)$ & \\
\hline Other & $9(16.7)$ & $4(7.4)$ & \\
\hline \multicolumn{4}{|l|}{ Histology } \\
\hline Infiltrating ductal carcinoma & $43(79.6)$ & $46(85.2)$ & 0.800 \\
\hline Infiltrating lobular carcinoma & $5(9.3)$ & $5(9.3)$ & \\
\hline Other & $6(11.1)$ & $3(5.6)$ & \\
\hline \multicolumn{4}{|l|}{ Tumor grade } \\
\hline Well/moderately differentiated & $18(33.3)$ & $13(24.1)$ & 0.148 \\
\hline Poorly/undifferentiated & $27(50.0)$ & $32(59.3)$ & \\
\hline Other & $4(7.4)$ & $1(1.9)$ & \\
\hline Unknown & $5(9.3)$ & $8(14.8)$ & \\
\hline \multicolumn{4}{|l|}{ ER status } \\
\hline ER negative & $18(33.3)$ & $22(40.7)$ & 0.398 \\
\hline ER positive & $27(50.0)$ & $23(42.6)$ & \\
\hline Other & $9(16.7)$ & $9(16.7)$ & \\
\hline \multicolumn{4}{|l|}{ PR status } \\
\hline PR negative & $19(35.2)$ & $22(40.7)$ & 0.458 \\
\hline PR positive & $25(46.3)$ & $21(38.9)$ & \\
\hline Other & $10(18.5)$ & $11(20.4)$ & \\
\hline \multicolumn{4}{|l|}{ Prior adjuvant chemotherapy } \\
\hline No therapy & $29(53.7)$ & $26(48.1)$ & 0.565 \\
\hline Yes therapy & $25(46.3)$ & $28(51.9)$ & \\
\hline \multicolumn{4}{|l|}{ Prior adjuvant hormonal therapy } \\
\hline No therapy & $31(57.4)$ & $40(74.1)$ & 0.070 \\
\hline Yes therapy & $23(42.6)$ & $14(25.9)$ & \\
\hline \multicolumn{4}{|l|}{ Prior metastatic hormonal therapy } \\
\hline No therapy & $39(72.2)$ & $41(75.9)$ & 0.662 \\
\hline Yes therapy & $15(27.8)$ & $13(24.1)$ & \\
\hline \multicolumn{4}{|l|}{ Response to therapy } \\
\hline Complete response (CR) & $3(5.6)$ & $5(9.3)$ & 0.5844 \\
\hline Partial response (PR) & $25(46.3)$ & $23(42.6)$ & \\
\hline Stable disease (SD) & $15(27.8)$ & $14(25.9)$ & \\
\hline Progressive disease (PD) & $9(16.7)$ & $7(13.0)$ & \\
\hline Other & $2(3.7)$ & $5(9.3)$ & \\
\hline
\end{tabular}

* $P$ is given for chi-square analysis. Statistically significant $P$ values $(P<0.05)$ are in bold.

${ }^{1} \mathrm{FAC}$, 5-fluorouracil-doxorubicin-cyclophosphamide combination

${ }^{2} \mathrm{TAC}$, docetaxel-doxorubicin- cyclophosphamide combination

$\mathrm{ER}$, estrogen receptor; $\mathrm{PR}$, progesterone receptor. 
block. TMA internal controls consisted of normal breast tissue, liver tissue and formalin fixed, paraffin embedded cell lines A431, BAF3, BT474, BT549, HT29, MB 231, MB435, MB436, MB468, MCF7, SKBR3, SW480, and T47D. Culture conditions and cell-line TMA construction have been previously published in detail [18]. Additionally, a specialized Index Array was constructed to confirm assay reproducibility within both Yale University and TAX $307 \mathrm{~S}$ cohorts and to normalize AQUA ${ }^{\circledR}$ scores between different immunostaining run dates. Finally, a non-tumor TMA containing normal breast tissue was constructed from breast reduction mammoplasties using 110 unique patient samples with two-fold redundancy $(n=220)$. The TAX $307 \mathrm{~S}$ cohort consisted of 140 conventional whole tissue (WT) slides of representative tumor tissue.

\section{Antibodies and immunofluorescence}

Yale University cohort TMAs and TAX 307S WT slides were immunostained using MAP-tau monoclonal antibody, which recognizes all human MAP-tau isoforms (1:750; mouse monoclonal, clone 2B2.100/T1029; US Biological, Swampscott, MA, USA). This antibody has been validated by western blot analysis and siRNA knock down [7]. For TAX 307S, serial sections of the index array TMA were stained alongside both cohorts to confirm assay reproducibility. Normal breast epithelium in the Yale University cohort TMAs and the TAX 307S WT slides served as internal positive controls, while omission of the primary antibody served as the negative control for each immunostaining event. Quantitative immunofluorescence staining was performed as previously described in detail (See Additional File 2).

\section{TMA image capture and analysis}

The AQUA method of quantitative immunofluorescence has been previously described [19]. The TMA cohorts were captured and analyzed using V1.6 of the AQUA ${ }^{\circledR}$ software (HistoRx, Branford, CT, USA) on the PM2000 platform. Specific parameters related to the TMA data collection are found in Additional File 2.

\section{Whole tissue image capture and analysis}

In contrast to TMA image acquisition and analysis, WT sections from the TAX 307 clinical trial cohort required a different approach for image capture and analysis. Based on the size and contours of each resection area per slide, an image acquisition matrix was created with fields of view (FOV) ranging from 4 to 486 discrete images per slide. To avoid sampling bias in tumor image selection and to address issues of potential MAP-tau tissue heterogeneity, all cytokeratin-stained regions (rather than a variable number of regions selected at random) were collected for each tissue and quantitatively analyzed. A total of 15,816 images were collected and assessed for MAP-tau expression from the 140 cases received from the TAX 307 clinical trial. Not all cases were available for evaluation with a total of 22 cases (15.7\%) missing due to tissue loss during staining or incomplete clinical trial data.

\section{Statistical analysis}

Average values for MAP-tau AQUA scores from the TMA were calculated from two-fold redundant samples and treated as independent continuous variables. The median expression level of MAP-tau from normal breast tissue served as the pre-defined cutpoint to differentiate high from low MAP-tau expression in both cohorts. Chisquare analysis was used to compare TAX 307S patient characteristics between FAC and TAC treatment groups to ensure intra-group comparability and to compare TAX 307S patient characteristics with those of the original TAX 307 clinical trial cohort. Survival curves for both cohorts were constructed using Kaplan Meier methods and the Cox-Mantel log-rank test was used to calculate the association between expression and survival. Two survival endpoints were used in this analysis. Overall survival (OS) was assessed for the Yale University cohort while TTP was evaluated for the TAX 307 clinical trial cohort. Cox proportional hazards regression analysis was used to determine which independent factors significantly impacted OS. Analyses used OS in the Yale University cohort and progression-free survival (PFS) in the TAX 307S cohort. To evaluate the association between patient response and MAP-tau expression levels, chisquare analysis was performed. Tau-by-treatment interaction was calculated to assess the relation between MAP-tau expression and docetaxel efficacy. All $P$ values were based on two-sided testing and differences were considered significant at $P<0.05$. Statistical analysis was performed using JMP Statistical Discovery Software, Version 7.0.1 (SAS Institute, Inc., Cary, NC, USA) and R, Version 2.8.0 (R Development Core Team).

\section{Results}

MAP-tau expression and distribution

In order to establish a cutpoint that could be used to differentiate high versus low MAP-tau expression in patients, MAP-tau was measured in normal epithelial ducts and lobules in TMA format $(n=220)$. Average MAP-tau expression scores in normal breast tissue showed mean and median AQUA scores of 489 and 462, respectively, with a score range of 157 to 1425 . The median MAP-tau expression score in normal breast tissue was subsequently used in all analyses to differentiate high expressers (AQUA score $\geq 462$ ) from low expressers 
(AQUA < 462). All subsequent AQUA scores were normalized to this AQUA score range using the index array TMA.

We examined MAP-tau expression within the Yale University cohort ( $\mathrm{n}=651$ ), and found cytoplasmic localization similar to our observations in normal breast tissue (Figure 1a). The frequency distribution of average MAP-tau expression scores in the Yale University cohort indicated mean and median AQUA scores of 498 and 210 , respectively, with a range of 54 to 3017 (Figure 1b). A total of 480 cases had sufficient tumor tissue for analysis with $22 \%$ classified as high MAP-tau expressers compared with $78 \%$ as low expressers.

Estrogen receptor (ER)-negative cases showed significantly more frequent low MAP-tau (48.6\%) compared with ER-positive cases $(29.9 \%)(P<0.0001)$ and this trend was mirrored for progesterone receptor (PR) status as well (Table 2). For HER2 expression, an inverse correlation between MAP-tau and human epidermal growth factor receptor (HER) 2-positive expression was observed with high MAP-tau present in only $2.4 \%$ of HER2-positive patients compared with $19.1 \%$ with high MAP-tau in
HER2-negative cases. This was a particularly interesting observation as MAP-tau exists adjacent to HER2 on the $17 q 12$ amplicon, yet rarely appears co-expressed in HER2-positive tumors. MAP-tau expression did not correlate with menopausal status, tumor size, nuclear grade, or nodal status (Table 2).

\section{MAP-tau prognostic value in the Yale University cohort} Patients with high MAP-tau expression $(\mathrm{n}=94)$ showed improved survival compared with those with low expression ( $\mathrm{n}=339$ ) $(68.3 \%$ vs $52.9 \%$, respectively; log-rank, $P=$ 0.006 , Figure $2 \mathrm{a}$ ). When stratified by ER status, MAP-tau showed prognostic value in ER-negative but not in ERpositive patients (Figure $2 \mathrm{~b}$ ). In the ER-negative/high MAP-tau expressers $(n=35)$ we observed improved survival compared with low expressers $(n=209 ; 78 \%$ vs $42 \%$; log-rank, $P=0.006$ ). Similarly, patients stratified by HER2 status showed improved survival for high MAPTau/HER2 positive expression compared with low MAPtau/HER2 positive expression (log rank $P=0.007$, Figure 2c), although the coexpression of MAP-tau and HER2 was a rare event. Univariate analysis showed that high

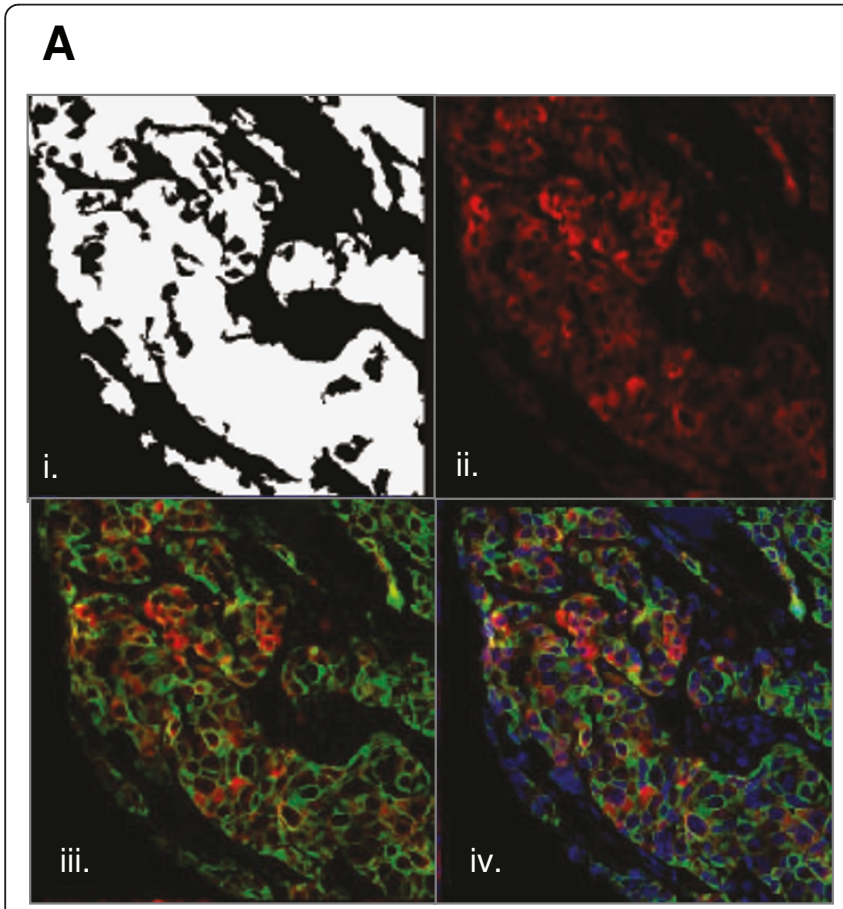

B

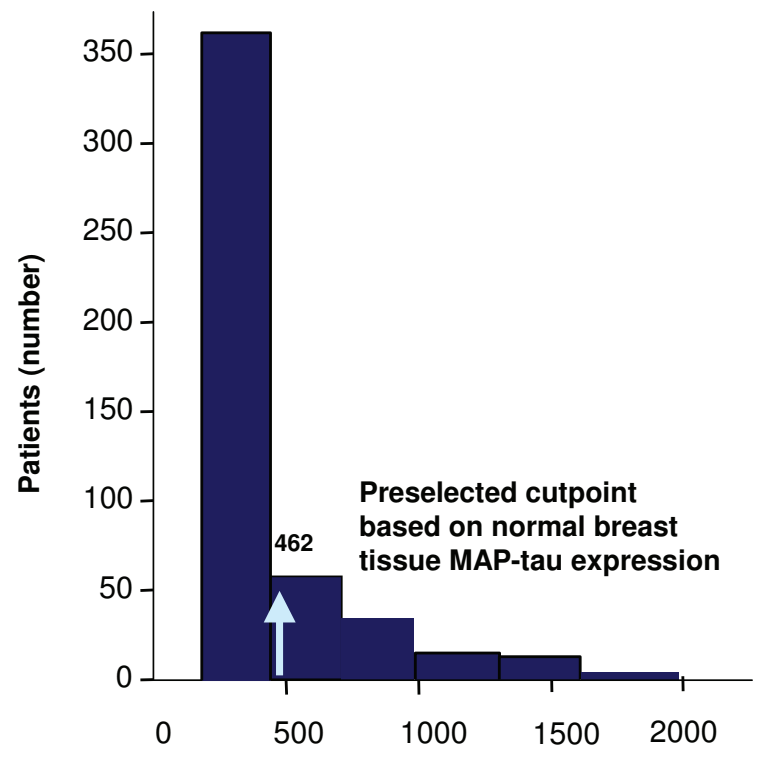

MAP-tau Expression in Yale Cohort (AQUA Score)

Figure 1 MAP-tau expression and frequency distribution in Yale University cohort with two-fold redundancy. (a) Representative case from the Yale University cohort TMA showing cytoplasmic localization of MAP-tau within breast tumor tissue (two-fold redundancy; $\mathrm{n}=651$ ). (i) Pixel binary gating demarcating epithelial tumor area from stroma in order to define the tumor compartment; (ii) immunofluorescence of MAPtau-Cy5 (red) expression pattern (continuous score of 789); (iii) target protein MAP-tau-Cy5 (red) colocalization with cytokeratin-Cy3, a marker for breast epithelia (green); (iv) Localization of nuclear DAPI (blue) relative to colocalization of target protein MAP-tau-Cy5 (red) with cytokeratin-Cy3, a marker for breast epithelia (green). Original magnification $\times 20$. (b) Yale frequency distribution of average MAP-tau expression scores in the Yale University cohort with preselected cutpoint 462, the median MAP-tau expression score observed in normal breast tissue and used to differentiate high expressors from low expressors. 
Table 2 Correlation between MAP-tau expression and clinicopathologic variables in the Yale University cohort

\begin{tabular}{|c|c|c|c|}
\hline \multirow[b]{2}{*}{ Variable } & \multicolumn{2}{|c|}{ MAP-tau expression } & \multirow[b]{2}{*}{$P^{*}$} \\
\hline & Low (\%) (AQUA score < 462) & High (\%) (AQUA score > 462) & \\
\hline \multicolumn{4}{|l|}{ Menopausal status } \\
\hline Premenopausal & $108(22.8)$ & $31(6.5)$ & 0.734 \\
\hline Postmenopausal & $265(55.9)$ & $70(14.8)$ & \\
\hline \multicolumn{4}{|l|}{ Tumor size } \\
\hline$<2 \mathrm{~cm}$ & $128(29.1)$ & $31(7.1)$ & 0.535 \\
\hline $2-5 \mathrm{~cm}$ & $155(35.2)$ & $50(11.4)$ & \\
\hline$>5 \mathrm{~cm}$ & $59(13.4)$ & $17(3.9)$ & \\
\hline \multicolumn{4}{|l|}{ Nuclear grade } \\
\hline Small/uniform nuclei & $60(13.4)$ & $15(3.4)$ & 0.225 \\
\hline Intermediate nuclei & $182(40.6)$ & $61(13.6)$ & \\
\hline Large nuclei & $107(23.9)$ & $23(5.1)$ & \\
\hline \multicolumn{4}{|l|}{ Nodal status } \\
\hline Node positive & $199(41.8)$ & $47(9.9)$ & 0.201 \\
\hline Node negative & $175(36.8)$ & 55 (11.6) & \\
\hline \multicolumn{4}{|l|}{ ER } \\
\hline Negative & $227(48.6)$ & $38(8.1)$ & $<0.0001$ \\
\hline Positive & $140(29.9)$ & $62(13.3)$ & \\
\hline \multicolumn{4}{|l|}{ PR } \\
\hline Negative & $240(52.4)$ & $31(6.8)$ & $<0.0001$ \\
\hline Positive & $120(26.2)$ & $67(14.6)$ & \\
\hline \multicolumn{4}{|l|}{ HER2 } \\
\hline Negative & $283(61.3)$ & $88(19.1)$ & 0.010 \\
\hline Positive & $80(17.3)$ & $11(2.4)$ & \\
\hline
\end{tabular}

${ }^{*} P$ is given for chi-square analysis. Statistically significant $P$ values $(P<0.05)$ are in bold.

ER, estrogen receptor; HER2, human epidermal growth factor receptor 2; PR, progesterone receptor.

MAP-tau expression and ER and PR positive status were associated with significantly better OS (hazard ratio $(\mathrm{HR})=0.766$ and $0.675 ; 95 \%$ confidence interval $(\mathrm{CI})$, 0.598 to 0.981 and 0.524 to.871, $P=0.0005$ and $P<$ 0.0001 , respectively), while large tumor size, nodal metastasis, increasing number of positive nodes, total nodes, and nuclear grade, were associated with worse OS (Table 3). In multivariate analysis, high MAP-tau expression was again associated with significantly improved OS. For patients with high MAP-tau expression, we observed a $24 \%$ reduction of risk $(\mathrm{HR}=0.765$; 95\% CI, 0.598 to $0.957, P=0.018$; Table 4). In contrast, large tumor size, nodal metastasis, increasing total nodes, and positive HER2 status were associated with worse OS.

MAP-tau expression pattern in TAX 307S

In the TAX 307S metastatic cohort, MAP-tau expression was measured in each WT section using a matrix comprised of FOVs. All FOVs were collected and AQUA scores were generated, but each region was reviewed on a serial H\&E slide to confirm that all FOVs represented infiltrating carcinoma. FOVs with normal breast ducts or ductal carcinoma in situ were excluded from the analysis. This process is illustrated in Figures $3 \mathrm{a}$ and $3 \mathrm{~b}$. Similar to the Yale University cohort, MAP-tau expression in TAX $307 \mathrm{~S}$ remained localized to the cytoplasmic compartment within the epithelial tumor area. A total of 15,816 individual, non-overlapping FOVs were evaluated in the TAX $307 \mathrm{~S}$ cohort. A frequency distribution summarizing the FOVs was generated for each case in the TAX 307S cohort (Figure 3c). The median score from all FOVs from each case was used to represent that case in the final subset of 108 cases. The distribution of MAP-tau expression in TAX307 for a single patient case is illustrated in Figure 3d. The median level of normal MAPtau expression as previously applied in the Yale 


\section{MAP-tau expression in the Yale University Cohort}
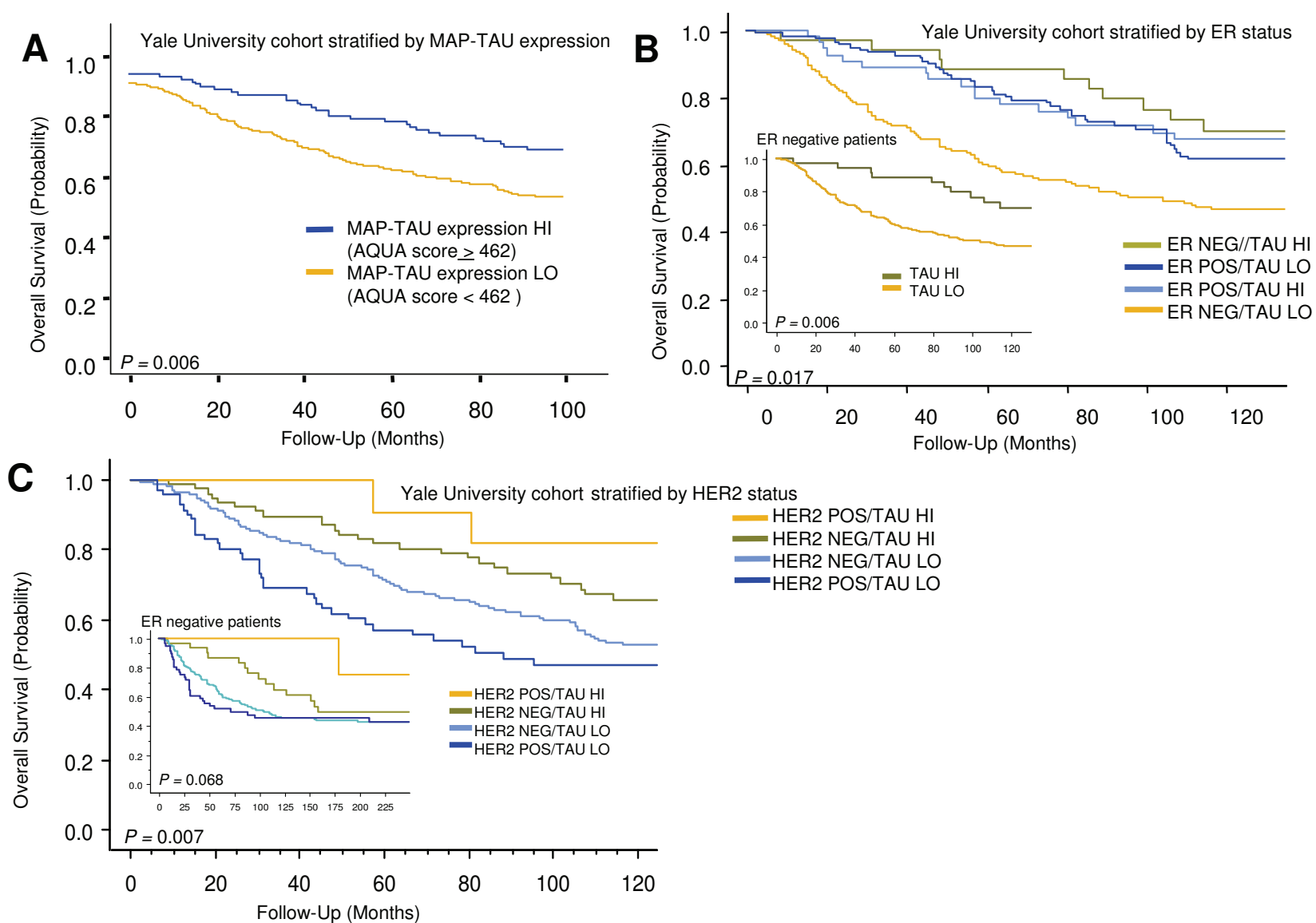

Figure 2 Kaplan Meier survival analysis and MAP-tau expression in Yale University cohort. (a) Ten-year survival for high MAP-tau expression versus low expression for all invasive breast carcinoma patients in the Yale University cohort $(n=651)$. Survival rate for patients classified as high MAP-tau expressors $(n=94)$ was $68.3 \%$ compared with $52.9 \%$ for low expressors $(n=339$; log-rank, $P=0.006)$. (b) Kaplan Meier survival for MAP-tau expression stratified by eatrogen receptor (ER) status in the Yale University cohort. For ER-negative patients (inset), high MAP-tau expression ( $n=35$ ) showed improved survival compared with low $(n=209)$ expression. (c) Ten-year survival for MAP-tau expression stratified by human epidermal growth factor receptor (HER) 2 status in the Yale University cohort. Patients classified as high MAP-Tau expressors showed improved survival compared with low expressors, regardless of HER2 status. For ER-negative patients stratified by HER2 status (inset), ER-negative patients with high MAP-tau expression $(n=30)$ trended toward improved survival, regardless of HER2 status, compared with low MAP-tau expressors $(n=56)(68.4 \% \vee 45.3 \%$; log-rank, $P=0.068)$.

University cohort was used to differentiate high from low expressers, and we observed 32\% (35 cases) expressing high MAP-tau compared with $68 \%$ (73 cases) showing low expression in TAX 307S (Table 5). This result is consistent with the MAP-tau expression distribution in the Yale University cohort (22\% high MAP-tau and 78\% low MAP-tau expression; $P=0.21$ and $P=0.43$, respectively).

In TAX 307S, as in the Yale cohort above, low MAPtau expression was significantly more frequent in ERnegative cases $(35.6 \%)$ compared with ER-positive cases (28.9\%; $P=0.005)$. MAP-tau expression was also associated with prior adjuvant chemotherapy (anthracyclines only) with low MAP-tau expression most frequently observed in patients receiving adjuvant chemotherapy (39.8\%). MAP-tau expression did not correlate with menopausal status, tumor size, tumor grade, nodal status, PR status, response to therapy, treatment arm, or prior adjuvant or metastatic endocrine therapy.

\section{MAP-tau prognostic value in TAX 307S}

Comparison analysis of TAC vs FAC treatment arms alone (not stratified by MAP-tau) in TAX $307 \mathrm{~S}$ showed no difference in TTP $(P=0.312$; Figure $4 \mathrm{a})$ and confirmed original TAX 307 clinical trial results which showed no differences in median TTP $(P=0.51)$ or OS $(P=0.93)$, with a median TTP of 31 versus 29 weeks and median OS of 21 versus 22 weeks for TAC versus FAC, respectively. Improved median five-year DFS was observed for patients in TAX 307 who received TAC versus FAC $(69 \%$ v $52 \% ; P=0.04)$ and the inclusion of 
Table 3 Univariate analysis of tumor and clinical risk factors for overall survival in the Yale University cohort

\begin{tabular}{|c|c|c|c|c|}
\hline \multirow[b]{2}{*}{ Variable } & \multicolumn{3}{|c|}{ Yale University cohort } & \multirow[b]{2}{*}{$P^{*}$} \\
\hline & No. of patients $(\%)(n=651)$ & HR & $95 \% \mathrm{Cl}$ & \\
\hline Age at diagnosis & $645(99.1)$ & 0.999 & $0.988-1.009$ & 0.890 \\
\hline Unknown/missing & $6(0.9)$ & & & \\
\hline \multicolumn{5}{|l|}{ Menopausal status } \\
\hline Premenopausal & $196(30.1)$ & 1.000 & & 0.436 \\
\hline Postmenopausal & $449(69.0)$ & 1.115 & $0.848-1.482$ & \\
\hline Unknown/missing & $6(0.9)$ & & & \\
\hline \multicolumn{5}{|l|}{ Tumor size $(\mathrm{cm})$} \\
\hline$\leq 2$ & $215(33.0)$ & 1.000 & & $<0.0001$ \\
\hline $2-5$ & $283(43.5)$ & 1.682 & $1.254-2.258$ & \\
\hline$\geq 5$ & $101(15.5)$ & 2.911 & $2.074-4.086$ & \\
\hline Other & $52(8.0)$ & & & \\
\hline \multicolumn{5}{|l|}{ Nodal status } \\
\hline Negative for node metastasis & $327(50.2)$ & 1.000 & & $<0.0001$ \\
\hline Positive for node metastasis & $320(49.2)$ & 2.286 & $1.795-2.910$ & \\
\hline Unknown/missing & $4(0.6)$ & & & \\
\hline Positive nodes & $320(49.2)$ & 1.022 & $1.001-1.042$ & 0.040 \\
\hline Total nodes & $625(96.0)$ & 0.978 & $0.961-0.994$ & 0.010 \\
\hline Unknown/missing & $26(4.0)$ & & & \\
\hline \multicolumn{5}{|l|}{ Nuclear grade } \\
\hline Small/uniform nuclei & $113(17.4)$ & 1.000 & & 0.0007 \\
\hline Intermediate nuclei & $315(48.4)$ & 1.231 & $0.854-1.818$ & \\
\hline Large nuclei & $170(26.1)$ & 1.594 & $1.192-2.123$ & \\
\hline Other & $53(8.1)$ & & & \\
\hline \multicolumn{5}{|l|}{ ER status } \\
\hline ER negative & $289(44.4)$ & 1.000 & & 0.0005 \\
\hline ER positive & $326(50.1)$ & 0.766 & $0.598-0.981$ & \\
\hline Other & $36(5.5)$ & & & \\
\hline \multicolumn{5}{|l|}{ PR status } \\
\hline PR negative & $294(45.2)$ & 1.000 & & $<0.0001$ \\
\hline PR positive & $302(46.4)$ & 0.675 & $0.524-0.871$ & \\
\hline Other & $55(8.4)$ & & & \\
\hline \multicolumn{5}{|l|}{ HER2 status } \\
\hline HER2 negative & $495(76.0)$ & 1.000 & & 0.153 \\
\hline HER2 positive & $109(16.7)$ & 1.270 & $1.048-1.317$ & \\
\hline Other & $47(7.2)$ & & & \\
\hline \multicolumn{5}{|l|}{ MAP-tau expression } \\
\hline MAP-tau low expression & $376(57.8)$ & 1.000 & & 0.0042 \\
\hline MAP-tau high expression & $104(16.0)$ & 0.691 & $0.489-0.974$ & \\
\hline Unknown/missing & $171(26.3)$ & & & \\
\hline
\end{tabular}

* $P$ is given for Cox univariate analysis, statistically significant $P$ values $(P<0.05)$ are in bold, trending $P$ values are in italics; $\mathrm{Cl}$, confidence interval; ER, estrogen receptor; HER2, human epidermal growth factor receptor 2; HR, hazard ratio; PR, progesterone receptor. 
Table 4 Cox proportional hazards multivariate model for overall survival in the Yale University cohort

\begin{tabular}{|c|c|c|c|c|}
\hline \multirow[b]{2}{*}{ Variable } & \multicolumn{3}{|c|}{ Yale University cohort } & \multirow[b]{2}{*}{$P^{*}$} \\
\hline & No. of patients $(\%)(n=651)$ & HR & $95 \% \mathrm{Cl}$ & \\
\hline Age at diagnosis & $645(99.1)$ & 1.004 & $0.981-1.026$ & 0.718 \\
\hline Unknown & $6(0.9)$ & & & \\
\hline \multicolumn{5}{|l|}{ Menopausal status } \\
\hline Premenopausal & $196(30.1)$ & 1.000 & & 0.339 \\
\hline Postmenopausal & $449(69.0)$ & 1.158 & $0.857-1.569$ & \\
\hline Other & $6(0.9)$ & & & \\
\hline \multicolumn{5}{|l|}{ Tumor size $(\mathrm{cm})$} \\
\hline$\leq 2$ & $215(33.0)$ & 1.000 & & $<0.0001$ \\
\hline $2-5$ & $283(43.5)$ & 1.880 & $1.255-2.865$ & \\
\hline$\geq 5$ & $101(15.5)$ & 1.988 & $1.323-2.951$ & \\
\hline Unknown & $52(8.0)$ & & & \\
\hline \multicolumn{5}{|l|}{ Nodal status } \\
\hline Negative for node metastasis & $327(50.2)$ & 1.000 & & $<0.0001$ \\
\hline Positive for node metastasis & $320(49.2)$ & 1.578 & $1.307-1.922$ & \\
\hline Unknown & $4(0.6)$ & & & \\
\hline Total nodes & $625(96.0)$ & 0.976 & $0.956-0.996$ & 0.022 \\
\hline Unknown & $26(4.0)$ & & & \\
\hline \multicolumn{5}{|l|}{ Nuclear grade } \\
\hline Small/uniform nuclei & $113(17.4)$ & 1.000 & & 0.421 \\
\hline Intermediate nuclei & $315(48.4)$ & 1.015 & $0.624-1.725$ & \\
\hline Large nuclei & $170(26.1)$ & 1.272 & $0.868-1.853$ & \\
\hline Unknown & $53(8.1)$ & & & \\
\hline \multicolumn{5}{|l|}{ ER status } \\
\hline ER negative & $289(44.4)$ & 1.000 & & 0.308 \\
\hline ER positive & $326(50.1)$ & 0.903 & $0.740-1.097$ & \\
\hline Unknown & $36(5.5)$ & & & \\
\hline \multicolumn{5}{|l|}{ PR status } \\
\hline PR negative & $294(45.2)$ & 1.000 & & 0.433 \\
\hline PR positive & $302(46.4)$ & 0.929 & $0.769-1.114$ & \\
\hline Unknown & $55(8.4)$ & & & \\
\hline \multicolumn{5}{|l|}{ HER2 status } \\
\hline HER2 negative & $495(76.0)$ & 1.000 & & 0.020 \\
\hline HER2 positive & $109(16.7)$ & 1.292 & $1.041-1.586$ & \\
\hline Unknown & $47(7.2)$ & & & \\
\hline \multicolumn{5}{|l|}{ MAP-tau expression } \\
\hline MAP-tau low expression & $376(57.8)$ & 1.000 & & 0.018 \\
\hline MAP-tau high expression & $104(16.0)$ & 0.765 & $0.598-0.957$ & \\
\hline Other & $171(26.3)$ & & & \\
\hline
\end{tabular}

* $P$ is given for Cox multivariate analysis, statistically significant $P$ values $(P<0.05)$ are in bold, trending $P$ values are in italics; $\mathrm{Cl}$, confidence interval; ER, estrogen receptor; HR, hazard ratio; HER2, human epidermal growth factor receptor 2; PR, progesterone receptor. 

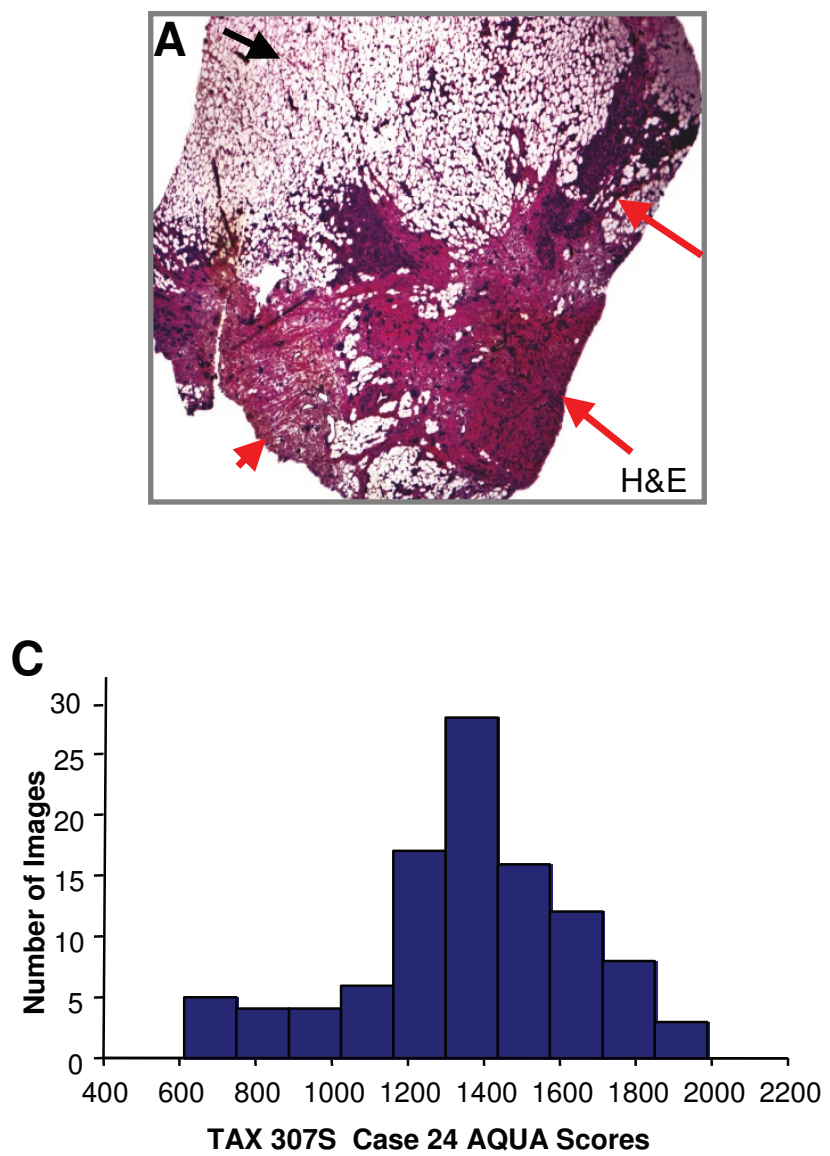

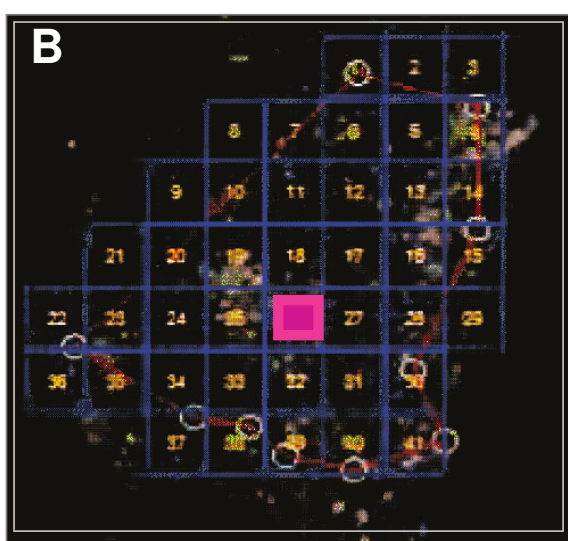

D

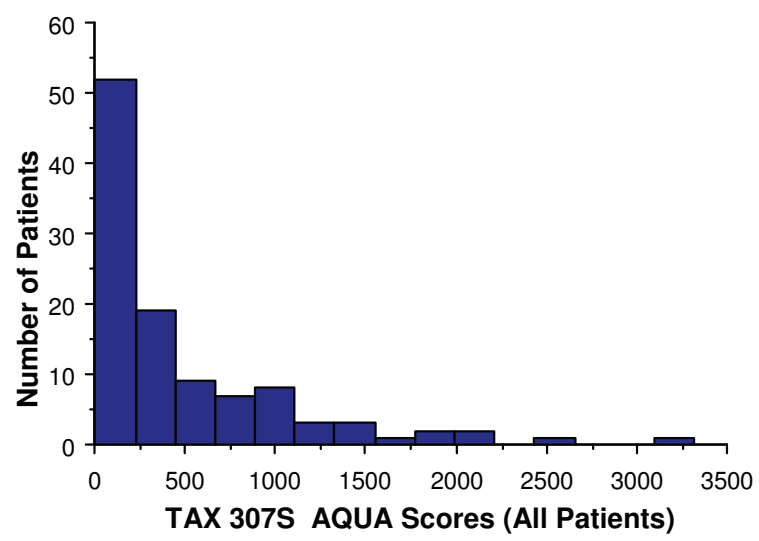

Figure 3 MAP-tau expression and frequency distribution in TAX 3075 whole tissue sections. (a) Whole section breast tumor tissue from patient case 24 stained with hematoxylin and eosin showing dark pink staining of tumor cytoplasm compared with blue nuclei staining (red arrows); remaining light pink or non-staining, mesh-like areas comprised of breast adipose tissue (black arrow). Original magnification $\times 4$. (b) Whole tissue slide of breast tumor tissue from panel a (case 24) stained with MAP-tau-Cy5 and analyzed using AQUA digital pathology algorithms. A matrix captured 103 quadrants (41 quadrants displayed in panel b and was used to systematically capture each field of view (FOV), creating 103 unique expression scores for case 24. Original magnification $\times 4$. (c) Frequency distribution for MAP-tau quadrant scores from case 24 with mean and median AQUA scores of 1357 and 1369, respectively, and a score range of 610 to 1986 . FOVs were used to generate a frequency distribution for each case in the TAX 3075 cohort $(n=140)$. The median AQUA score from each case was used in all cohort analyses. (d) Distribution of MAP-tau expression in TAX307.

docetaxel resulted in higher overall response rates for TAC versus FAC (55\% vs $44 \%$; $P=0.02$ ) [16].

When TAX 307S (TAC plus FAC arms combined) was stratified by MAP-tau expression, we observed prognostic value for MAP-tau with improved median time to PFS for high MAP-tau expressers ( $\mathrm{n}=35$ ) compared with low expressers ( $\mathrm{n}=73 ; 33.0 \mathrm{v} 23.4$ months) and a mean TTP of 31.2 months (log-rank, $P=0.010$; Figure $4 \mathrm{~b}$ ), suggesting that this marker maintains prognostic value in metastatic patients.

\section{MAP-tau predictive value in TAX 307S}

Stratification by both treatment arm and MAP-tau expression showed improved TTP for high MAP-tau expression, regardless of treatment, which indicated prognostic but not predictive value for MAP-tau (Figure 4c, log-rank, $P=$ 0.006). In addition, no significant interaction between MAP-tau expression and benefit from docetaxel $(P=$ 0.843 ) was observed further confirming the finding of no predictive value for MAP-tau in TAX 307S. High MAPtau expression was associated with improved PFS (HR: 0.538 ; $95 \% \mathrm{CI}, 0.333$ to $0.871 ; P=0.011$ ), whereas tumor non-response (stable disease plus progressive disease) was associated with worse PFS (HR: 2.213; 95\% CI, 1.404 to 3.488; $P=0.0006$; Table 6). Multivariate Cox proportional hazards regression analysis showed only high MAP-tau expression was associated with significantly better TTP. For these patients, we observed a $69 \%$ reduction of risk of progression $(\mathrm{HR}=0.308 ; 95 \% \mathrm{CI}, 0.130$ to $0.728, P=$ 0.007; Table 7). 
Table 5 Correlation between MAP-tau expression and clinicopathologic variables in TAX 3075

\begin{tabular}{|c|c|c|c|}
\hline \multirow[b]{2}{*}{ Variable } & \multicolumn{2}{|c|}{ MAP-tau expression } & \multirow[b]{2}{*}{$P^{*}$} \\
\hline & Low (\%) (AQUA score < 462) & High (\%) (AQUA score > 462) & \\
\hline \multicolumn{4}{|l|}{ Menopausal status } \\
\hline Premenopausal & $15(17.1)$ & $9(10.2)$ & 0.487 \\
\hline Postmenopausal & $45(51.1)$ & 19 (21.6) & \\
\hline \multicolumn{4}{|l|}{ Tumor size $(\mathrm{cm})$} \\
\hline$\leq 2$ & $13(12.8)$ & $11(10.8)$ & 0.137 \\
\hline $2-5$ & $40(39.2)$ & $16(15.6)$ & \\
\hline$\geq 5$ & $15(14.7)$ & $7(6.9)$ & \\
\hline \multicolumn{4}{|l|}{ Nodal status } \\
\hline Negative for node metastasis & $23(24.2)$ & $10(10.5)$ & 0.922 \\
\hline Positive for node metastasis & $41(43.2)$ & $21(22.1)$ & \\
\hline Tumor grade & & & 0.140 \\
\hline Well/moderately differentiated & $19(21.1)$ & $12(13.3)$ & \\
\hline Poorly/undifferentiated & $45(50.0)$ & $14(15.6)$ & \\
\hline \multicolumn{4}{|l|}{ ER status } \\
\hline ER negative & $32(35.6)$ & $8(8.9)$ & 0.005 \\
\hline ER positive & $26(28.9)$ & $24(26.7)$ & \\
\hline \multicolumn{4}{|l|}{ PR status } \\
\hline PR negative & $30(34.5)$ & $11(12.6)$ & 0.103 \\
\hline PR positive & $26(29.9)$ & $20(22.9)$ & \\
\hline \multicolumn{4}{|l|}{ Prior adjuvant chemotherapy } \\
\hline No therapy & $30(27.8)$ & $25(23.2)$ & 0.002 \\
\hline Yes therapy & $43(39.8)$ & $10(9.3)$ & \\
\hline \multicolumn{4}{|l|}{ Prior adjuvant hormonal therapy } \\
\hline No therapy & $47(43.5)$ & $24(22.2)$ & 0.666 \\
\hline Yes therapy & $26(24.1)$ & $11(10.2)$ & \\
\hline \multicolumn{4}{|l|}{ Prior metastatic hormonal therapy } \\
\hline No therapy & $56(51.9)$ & $24(22.2)$ & 0.371 \\
\hline Yes therapy & $17(15.7)$ & $11(10.2)$ & \\
\hline \multicolumn{4}{|l|}{ Response to therapy } \\
\hline Complete response (CR) & $6(5.9)$ & $2(1.9)$ & 0.518 \\
\hline Partial response (PR) & $30(29.7)$ & $18(17.8)$ & \\
\hline Stable disease (SD) & $20(19.8)$ & $9(8.9)$ & \\
\hline Progressive disease (PD) & $13(12.9)$ & $3(2.9)$ & \\
\hline \multicolumn{4}{|l|}{ Treatment } \\
\hline$F A C^{1}$ & $39(36.1)$ & $15(13.9)$ & 0.303 \\
\hline $\mathrm{TAC}^{2}$ & $34(31.5)$ & $20(18.5)$ & \\
\hline
\end{tabular}

${ }^{*} P$ is given for chi-square analysis. Statistically significant $P$ values $(P<0.05)$ are in bold.

${ }^{1}$ FAC, 5-fluorouracil-doxorubicin-cyclophosphamide combination

${ }^{2} \mathrm{TAC}$, docetaxel-doxorubicin-cyclophosphamide combination

ER, estrogen receptor; PR, progesterone receptor. 


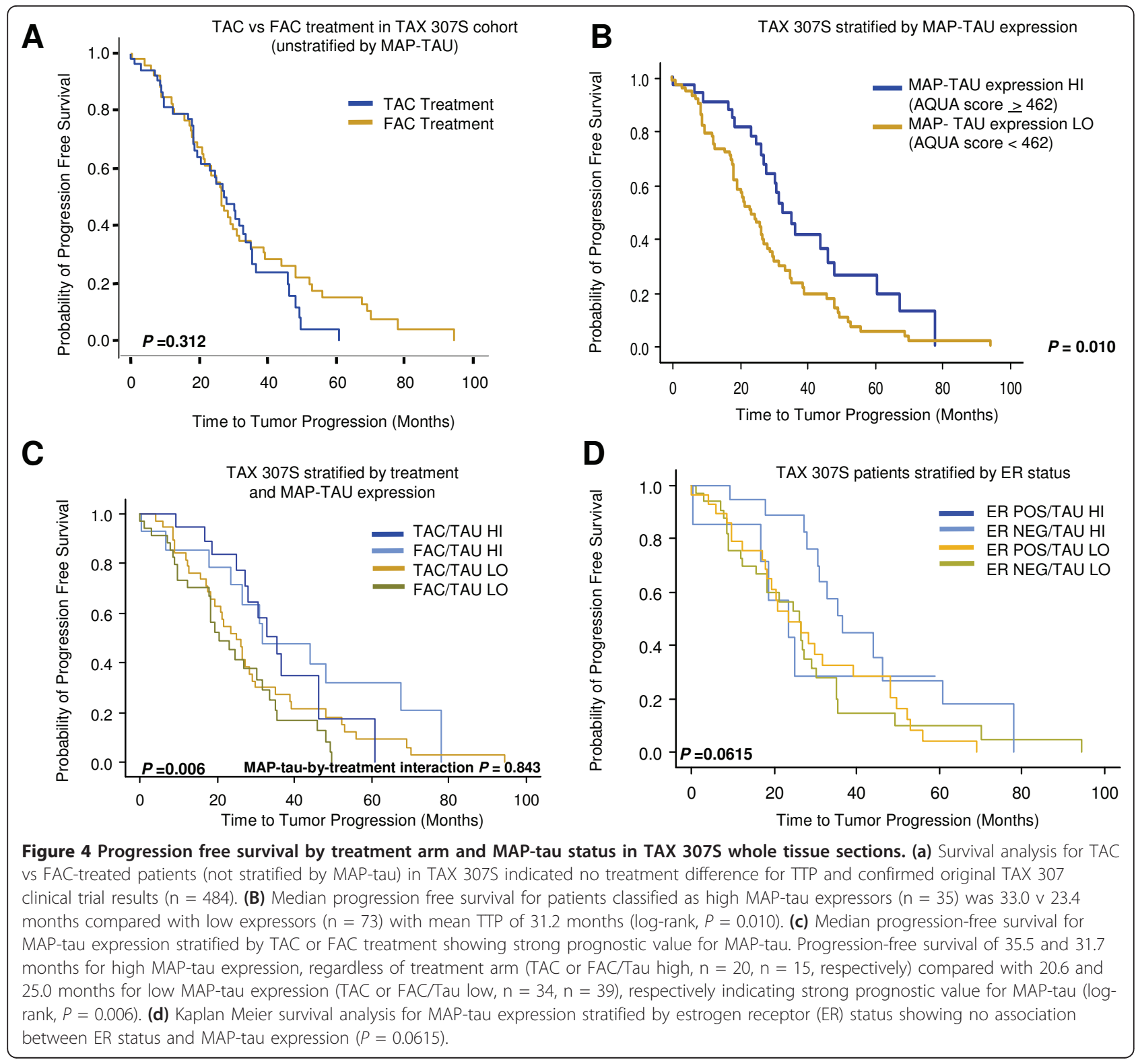

MAP-tau is an ER-regulated gene with inducible expression by both estrogen and tamoxifen, in vitro [20]. ER positivity and/or tamoxifen therapy could act by artificially elevating MAP-tau levels and obscuring the relation between MAP-tau expression level and response to taxane therapy. Thus we stratified this cohort by adjuvant endocrine therapy, ER status, and also TAC vs FAC treatment. Stratification by ER status showed a trend, but not significant association between MAP-tau expression and TTP (Figure 4d, log-rank, $P=$ 0.0615). Next, we correlated MAP-tau expression levels with response to docetaxel therapy. Response rates as a function of MAP-tau expression did not differ when split by ER status, adjuvant endocrine therapy, or taxane treatment arm (TAC vs FAC; Table 8).

\section{Discussion}

Although previous literature shows conflicting results for MAP-tau prognostic and predictive value, in this study of two independent cohorts, we find MAP-tau expression has prognostic value. In both a population-based retrospective cohort, and a randomized clinical trial with taxane as the only variable and uniformly treated metastatic patients, high levels of MAP-tau, a microtubule stabilizing protein, were associated with better outcomes. Increased microtubule stability may be associated with less aggressive tumors. However, the mechanistic reason for this observation is unknown. Furthermore, there is no correlation with nuclear grade in either cohort, suggesting that MAP-tau is not related to the molecular parameters that drive the morphological features contributing to nuclear grade. 
Table 6 Univariate analysis of tumor and clinical risk factors for progression-free survival in TAX 3075

\begin{tabular}{|c|c|c|c|c|}
\hline \multirow[b]{2}{*}{ Variable } & \multicolumn{3}{|c|}{ TAX 307S cohort } & \multirow[b]{2}{*}{$P^{*}$} \\
\hline & No. of patients $(n=140)$ & HR & $95 \% \mathrm{Cl}$ & \\
\hline Age & $108(77.1)$ & 0.977 & $0.955-1.00$ & 0.060 \\
\hline Other & $10(7.1)$ & & & \\
\hline Unknown & $22(15.7)$ & & & \\
\hline
\end{tabular}

Menopausal status

Premenopausal

Tumor size $(\mathrm{cm})$

$\begin{array}{ll}\leq 2 & 24(17.1) \\ 2-5 & 56(40.0) \\ \geq 5 & 22(15.8) \\ \text { Other } & 15(10.7) \\ \text { Unknown } & 23(16.4)\end{array}$

Nodal status

Negative for node metastasis

Positive for node metastasis

$33(23.6)$

1.000

$62(44.3)$

Other

$23(16.4)$

Unknown

\section{Tumor grade}

Well/moderately differentiated

Poorly/undifferentiated

$28(20.1)$

Unknown

$22(15.7)$

\section{ER status}

ER negative

ER positive

Unknown

$22(15.7)$

\section{PR status}

PR negative

Unknown

$22(15.7)$

\section{Prior adjuvant chemotherapy}

No therapy

Yes therapy

$10(7.1)$

Unknown

Prior adjuvant hormonal therapy

No therapy 
Table 6 Univariate analysis of tumor and clinical risk factors for progression-free survival in TAX 307S (Continued)

\begin{tabular}{ll}
\hline Other & $10(7.1)$ \\
& $22(15.7)$
\end{tabular}

\section{Prior metastatic hormonal therapy}

$\begin{array}{lr}\text { No therapy } & 80(57.1) \\ \text { Yes therapy } & 28(20.0) \\ \text { Other } & 10(7.1) \\ \text { Unknown } & 22(15.7)\end{array}$

Response to therapy

Responder

Non-responder

Other

Unknown

Treatment

$\begin{array}{lr}\mathrm{FAC}^{1} & 54(38.6) \\ \mathrm{TAC}^{2} & 54(38.6) \\ \text { Other } & 10(7.1) \\ \text { Unknown } & 22(15.7)\end{array}$

Unknown

\section{MAP-tau expression}

MAP-tau low expression

Other

* $P$ is given for Cox multivariate analysis, statistically significant $P$ values $(P<0.05)$ are in bold, trending $P$ values are in italics;

${ }^{1} \mathrm{FAC}$, 5 -fluorouracil-doxorubicin-cyclophosphamide combination

${ }^{2} \mathrm{TAC}$, docetaxel-doxorubicin- cyclophosphamide combination

$\mathrm{Cl}$, confidence interval; ER, estrogen receptor; HR, hazard ratio; PR, progesterone receptor.

Table 7 Cox proportional hazards multivariate model in TAX 307S

\begin{tabular}{|c|c|c|c|c|}
\hline \multirow[b]{2}{*}{ Variable } & \multicolumn{3}{|c|}{ TAX 3075 cohort } & \multirow[b]{2}{*}{$P^{*}$} \\
\hline & No. of patients $(\%)(n=140)$ & HR & $95 \% \mathrm{Cl}$ & \\
\hline Age & $108(77.1)$ & 0.972 & $0.934-1.011$ & 0.153 \\
\hline Other & $10(7.1)$ & & & \\
\hline Unknown & $22(15.7)$ & & & \\
\hline \multicolumn{5}{|l|}{ Tumor size $(\mathrm{cm})$} \\
\hline$\leq 2$ & $24(17.1)$ & 1.000 & & 0.224 \\
\hline $2-5$ & $56(40.0)$ & 1.116 & $0.280-4.444$ & \\
\hline$\geq 5$ & $22(15.8)$ & 1.326 & $0.433-4.065$ & \\
\hline Other & $15(10.7)$ & & & \\
\hline Unknown & $23(16.4)$ & & & \\
\hline \multicolumn{5}{|l|}{ Nodal status } \\
\hline Negative for node metastasis & $33(23.6)$ & 1.000 & & 0.207 \\
\hline Positive for node metastasis & $62(44.3)$ & 3.364 & $0.792-14.297$ & \\
\hline Other & $23(16.4)$ & & & \\
\hline Unknown & $22(15.7)$ & & & \\
\hline
\end{tabular}


Table 7 Cox proportional hazards multivariate model in TAX 3075 (Continued)

\section{Tumor grade}

Well/moderately differentiated

Other

Unknown

\section{ER status}

ER negative

ER positive

Unknown

\section{PR status}

PR negative

PR positive

Other

$31(22.1)$

Unknown

\section{Prior adjuvant chemotherapy}

No therapy

Yes therapy

Unknown

Prior adjuvant hormonal therapy

No therapy

Yes therapy

Other

Unknown

\section{Prior metastatic hormonal therapy}

$\begin{array}{lr}\text { No therapy } & 80(57.1) \\ \text { Yes therapy } & 28(20.0) \\ \text { Other } & 10(7.1) \\ \text { Unknown } & 22(15.7)\end{array}$

\section{Treatment}

$F^{\prime} C^{1}$

$\mathrm{TAC}^{2}$

Other

Unknown

$$
22(15.7)
$$

\section{MAP-tau expression}

$\begin{array}{lccc}\text { MAP-tau low expression } & 73(52.1) & 1.000 & \mathbf{0 . 0 0 7} \\ \text { MAP-tau high expression } & 35(25.0) & 0.308 & 0.130-0.728 \\ \text { Other } & 10(7.1) & & \\ \text { Unknown } & 22(15.7) & \end{array}$

${ }^{*} P$ is given for Cox multivariate analysis, statistically significant $P$ values $(P<0.05)$ are in boldface, trending values are in italics; $\mathrm{Cl}$, confidence interval; $\mathrm{ER}$, estrogen receptor; $\mathrm{HR}$, hazard ratio; PR, progesterone receptor.

${ }^{1}$ FAC, 5-fluorouracil-doxorubicin-cyclophosphamide combination.

${ }^{2} \mathrm{TAC}$, docetaxel-doxorubicin-cyclophosphamide combination. 
Table 8 MAP-tau expression levels and response to docetaxel in TAX 307S

TAX 307S Patient groups N Objective response $^{4}$ Stable disease $^{5}$
(CR + PR) (\%)

(SD) (\%)

ER positive

High MAP-tau

Low MAP-tau

Total

50

15 (33.3)

5 (11.1)

10 (22.2)

25 (55.8)

$10(22.2)$

15 (33.3)

ER negative

High MAP-tau

Low MAP-tau

Total

$4(10.5)$
$15(39.5)$
$19(49.9)$

$4(10.5)$

$13(34.2)$

17 (44.8)

FAC $^{1}$ and TAC $^{2}$

High MAP-tau

Low MAP-tau

Total

$\mathrm{TAC}^{2}$ only

High MAP-tau

Low MAP-tau

Total

$17(34.7)$

20 (19.7)

9 (8.9)

36 (35.6

20 (19.8)

108

56 (55.4)

29 (28.7)

14 (28.6)
Progressive disease

(PD) (\%)

$1(2.2)$

4 (8.9)

$5(11.1)$
Total

Missing

$P^{*}$

0.174

$21(46.7)$

24 (53.3)

$45(100.0) \quad 5$

0.721

$8(21.0)$

$30(78.9$

$38(100.0) \quad 2$

$2(5.3)$

0.518

$32(31.7)$

69 (68.3)

$13(12.9)$

$16(15.8)$

101

(100.0)

0.250

19 (38.8)

$30(61.2)$

$49(100.0)$

7 (14.3)

$1(2.0)$

$\mathrm{TAC}^{2}$ and ER positive

High MAP-tau

Low MAP-tau

Total

20

$\begin{array}{ll}9(45.0) & 4(20.0) \\ 2(10.0) & 3(15.0) \\ 11(55.0) & 7(35.0)\end{array}$

1 (5.0)

1 (5.0)

2 (10.0)

$6(30.0)$

$20(100.0) \quad 0$

7 (35.0)

0.520

$\mathrm{TAC}^{2} / \mathrm{ER}$ negative/Adj Hormonal -negative ${ }^{3}$

High MAP-tau

Low MAP-tau

0.222

$\begin{array}{cccccc}2(10.0) & 2(10.0) & 0(0.0) & 4(20.0) & \\ 8(40.0) & 3(15.0) & 5(25.0) & 16(80.0) & \\ 20 & 10(50.0) & 5(25.0) & 5(25.0) & 20(100.0) & 0\end{array}$

$\mathrm{FAC}^{1}$ only

High MAP-tau

Low MAP-tau

Total

$\begin{array}{lll} & 9(17.3) & 2(3.9) \\ & 19(36.6) & 13(25.0) \\ 54 & 28(53.9) & 15(28.9)\end{array}$

$2(3.9)$

$13(25.0)$

39 (75.0)

$52(100.0) \quad 2$

$F A C^{1}$ and ER positive

High MAP-tau

Low MAP-tau

Total

$\begin{array}{rll}6(24.0) & 1(4.0) \\ 8(32.0) & 7(28.0) \\ 14(56.0) & 8(32.0)\end{array}$

$9(17.3)$

0.514

Total

$14(56.0)$

8 (32.0)

$0(0.0)$

7 (28.0)

$18(72.0)$

$25(100.0)$

0.105

FAC ${ }^{1}$ and ER negative

High MAP-tau

$2(11.1) \quad 1(5.6)$

3 (12.0)

3 (12.0)

0.919

Low MAP-tau

7 (38.9)

$5(27.8)$

1 (5.6)

4 (22.2)

Total

18

$9(50.0)$

6 (33.3)

2 (11.1)

$14(77.8)$

$18(100.0) \quad 0$

${ }^{*} P$ is given for chi-square analysis. Statistically significant $P$ values $(P<0.05)$ are in bold.

${ }^{1} \mathrm{FAC}$, 5-fluorouracil-doxorubicin-cyclophosphamide combination

${ }^{2}$ TAC, docetaxel-doxorubicin-cyclophosphamide combination

${ }^{3}$ Adjuvant hormonal therapy-negative patients only

${ }^{4}$ Objective response, complete response $(C R)+$ partial response $(P R)$

${ }^{5}$ Stable disease defined as minimum of 6 weeks ( 2 cycles) ER, estrogen receptor; PR, progesterone receptor 
Although only one of our cohorts is useful to assess predictive value, we find no evidence for use of this marker as a companion diagnostic test to predict response to taxane therapy. A previous study showed mechanistic evidence for competitive binding between taxanes and MAP-tau [7]. That finding generated the hypothesis that expression levels of MAP-tau would be predictive of the effect of taxanes. However, this study is now the second cohort to fail to show an association between MAP-tau expression levels and response to taxane therapy in the metastatic setting. Although both studies [15] are relatively small, the lack of association in either case raises question regarding the value of measuring MAP-tau in large taxane trials.

Previous studies have shown interactions between taxane therapy and standard breast cancer biomarkers such as ER and HER2 [21-23]. There is a good mechanistic explanation for this finding in the case of ER because MAP-tau is induced by activation of ER by either estrogen or other selective-estrogen receptor modulators (tamoxifen) [20]. When the Yale cohort was stratified by ER status, MAP-tau expression was prognostic only in ER-negative patients. Multivariate analysis indicated that high MAP-tau remained a significant predictor of improved survival for ER-negative patients even after adjusting for tumor size and nodal status. As the ERnegative tumors are presumed to have lost ER function, the presence of MAP-tau may be regulated by other mechanisms. It is also possible that some of the ER-negative cases are really low positives or false negatives. In another study of this cohort, approximately $10 \%$ of the ER-negative cases were shown to be ER positive [24]. Furthermore, in an analysis not shown, we find a correlation between ER expression and MAP-tau expression raising the possibility that high MAP-tau is a surrogate for ER. However, the relatively small numbers of patients in these subgroups make it difficult to drawn convincing conclusions. Previous efforts to examine MAP-tau protein expression as a function of ER status have shown no prognostic value [12]. Other studies examining MAP-tau mRNA have also observed no prognostic value when stratified by ER status [11]. However, Andre and colleagues examined mRNA expression in a treated ER-positive cohort and showed low MAP-tau was associated with worse outcome $[9,12]$. The lack of agreement between these studies may be due to disparities between RNA and protein expression.

\section{Conclusions}

In this study of two independent cohorts, MAP-tau protein expression is shown to be prognostic but has no predictive value for response to docetaxel. The data from this and other studies is based largely on small, single-institution, retrospective studies. However, the lack of a promising result makes it difficult to justify measurement of MAP-tau in the clinical setting or even one of the cooperative group trials for taxane therapy. This is disappointing because a companion diagnostic test for taxane class drugs would be valuable. Future efforts evaluating other MAPs are needed and may be more fruitful.

\section{Additional material}

Additional file 1: Supplemental Table 1: Yale University cohort characteristics. Yale University cohort characteristics.

Additional file 2: Supplemental methods. Description of antibodies, immunofluorescence procedures, and image capture and analysis.

\section{Abbreviations}

Cl: confidence interval; ER: estrogen receptor; FAC: 5-fluorouracil: adriamycin: cyclophosphamide; FOV: field of view; HeCOG: Hellenic Cooperative Oncology Group; HER: human epidermal growth factor receptor; HR: hazard ratio; MAP: microtubule-associated protein; OS: overall serviva; PFS: progression-free survival; PR: progesterone receptor; TAC: docetaxeldoxorubicin-cyclophosphamide; TMA: tissue microarray; TTP: time to progression; WT: whole tissue (slides).

\section{Acknowledgements}

This work was funded by the Department of Defense Predoctoral Traineeship, USAMRMC Breast Cancer Research Program Grant \#W81XWH-061-0746 to MTB.

\section{Author details}

${ }^{1}$ Yale University School of Medicine, Department of Pathology, 310 Cedar St, New Haven, CT 06520, USA. ${ }^{2}$ Yale University School of Medicine, Department of Computational Biology, 333 Cedar Street, New Haven, CT 06510, USA. ${ }^{3}$ HistoRx, 35 Northeast Industrial Road, Branford, Connecticut, 06405, USA. ${ }^{4}$ Sanofi-Aventis, International Clinical Trial Management/Oncology, 200 Crossing Blvd. Bridgewater, NJ 08807, USA. ${ }^{5}$ Yale University School of Medicine, Department of Epidemiology and Public Health, 500 College St, New Haven, CT 06511, USA. ${ }^{6}$ Yale University School of Medicine, Department of Clinical Oncology, 333 Cedar Street, New Haven, CT 06510, USA.

\section{Authors' contributions}

MTB contributed to the design of the study, collected, analyzed and interpreted the data, and drafted the manuscript. $\mathrm{KL}$ and $\mathrm{AM}$ assisted with statistical analysis of the data. MG assisted with quantitative data collection. $\mathrm{KB}$ and FA provided patient clinicopathologic information. RLC and DLR reviewed patient tumor sections. LH and DLR contributed to the conception and design of the study, data interpretation and drafting of the manuscript. All authors read and approved the final manuscript.

\section{Competing interests}

Drs Rimm and Camp are stockholders in, and consultants to HistoRx, the exclusive licensee of the Yale-held patent on the AQUA technology. Mark Gustavson is an employee of HistoRx and Kimberly Bassi and Franck Appia are employees of Sanofi Aventis.

Received: 4 March 2011 Revised: 14 July 2011

Accepted: 2 November 2011 Published: 2 November 2011

\section{References}

1. Trudeau M, Charbonneau F, Gelmon K, Laing K, Latreille J, Mackey J, McLeod D, Pritchard K, Provencher L, Verma S: Selection of adjuvant chemotherapy for treatment of node-positive breast cancer. Lancet Oncol 2005, 6:886-898.

2. Nowak AK, Wilcken NR, Stockler MR, Hamilton A, Ghersi D: Systematic review of taxane-containing versus non-taxane-containing regimens for 
adjuvant and neoadjuvant treatment of early breast cancer. Lancet Oncol 2004, 5:372-380.

3. Esteva FJ, Valero V, Pusztai L, Boehnke-Michaud L, Buzdar AU, Hortobagyi GN: Chemotherapy of metastatic breast cancer: what to expect in 2001 and beyond. Oncologist 2001, 6:133-146.

4. Rosenberg KJ, Ross JL, Feinstein HE, Israelachvili J: Complementary dimerization of microtubule-associated tau protein: implications for microtubule bundling and tau-mediated pathogenesis. Proc Natl Acad Sci USA 2008, 105:7445-7450.

5. Felgner H, Frank R, Biernat J, Mandelkow EM, Mandelkow E, Ludin B, Matus A, Schliwa M: Domains of neuronal microtubule-associated proteins and flexural rigidity of microtubules. J Cell Biol 1997, 138:1067-1075.

6. Choi MC, Raviv U, Miller HP, Gaylord MR, Kiris E, Ventimiglia D, Needleman DJ, Kim MW, Wilson L, Feinstein SC, Safinya CR: Human microtubule-associated-protein tau regulates the number of protofilaments in microtubules: a synchrotron x-ray scattering study. Biophys J 2009, 97:519-527.

7. Rouzier R, Rajan R, Wagner P, Hess KR, Gold DL, Stec J, Ayers M, Ross JS, Zhang P, Buchholz TA, Kuerer H, Green M, Arun B, Hortobagyi GN, Symmans WF, Pusztai L: Microtubule-associated protein tau: a marker of paclitaxel sensitivity in breast cancer. Proc Natl Acad Sci USA 2005, 102:8315-8320.

8. Ross JL, Santangelo CD, Makrides V, Fygenson DK: Tau induces cooperative Taxol binding to microtubules. Proc Natl Acad Sci USA 2004, 101:12910-12915.

9. Andre F, Hatzis C, Anderson K, Sotiriou C, Mazouni C, Mejia J, Wang B, Hortobagyi GN, Symmans WF, Pusztai L: Microtubule-associated proteintau is a bifunctional predictor of endocrine sensitivity and chemotherapy resistance in estrogen receptor-positive breast cancer. Clin Cancer Res 2007, 13:2061-2067.

10. Rody A, Karn T, Ruckhaberle E, Müller V, Gehrmann M, Solbach C, Ahr A, Gätje R, Holtrich U, Kaufmann M: Gene expression of topoisomerase II alpha (TOP2A) by microarray analysis is highly prognostic in estrogen receptor (ER) positive breast cancer. Breast Cancer Res Treat 2009, 113:457-466.

11. Pentheroudakis G, Kalogeras KT, Wirtz RM, Grimani I, Zografos G, Gogas H, Stropp U, Pectasides D, Skarlos D, Hennig G, Samantas E, Bafaloukos D, Papakostas P, Kalofonos HP, Pavlidis N, Fountzilas G: Gene expression of estrogen receptor, progesterone receptor and microtubule-associated protein Tau in high-risk early breast cancer: a quest for molecular predictors of treatment benefit in the context of a Hellenic Cooperative Oncology Group trial. Breast Cancer Res Treat 2009, 116:131-143.

12. Pusztai L, Jeong JH, Gong Y, Ross JS, Kim C, Paik S, Rouzier R, Andre F, Hortobagyi GN, Wolmark N, Symmans WF: Evaluation of microtubuleassociated protein-Tau expression as a prognostic and predictive marker in the NSABP-B 28 randomized clinical trial. J Clin Oncol 2009, 27:4287-4292.

13. Bernard-Marty C, Treilleux I, Dumontet C, Cardoso F, Fellous A, Gancberg D, Bissery MC, Paesmans M, Larsimont D, Piccart MJ, Di Leo A: Microtubuleassociated parameters as predictive markers of docetaxel activity in advanced breast cancer patients: results of a pilot study. Clin Breast Cancer 2002, 3:341-345.

14. Tanaka S, Nohara T, Iwamoto M, Sumiyoshi K, Kimura K, Takahashi Y, Tanigawa N: Tau expression and efficacy of paclitaxel treatment in metastatic breast cancer. Cancer Chemother Pharmacol 2009, 64:341-346.

15. Shao YY, Kuo KT, Hu FC, Lu YS, Huang CS, Liau JY, Lee WC, Hsu C, Kuo WH, Chang K, Lin CH, Cheng AL: Predictive and prognostic values of tau and ERCC1 in advanced breast cancer patients treated with paclitaxel and cisplatin. Jpn J Clin Oncol 2010, 40:286-293.

16. Mackey J, Paterson A, Dirix L, et al: Final results of the phase III randomized trial comparing docetaxel $(T)$, doxorubicin $(A)$ and cyclophosphamide (C) to FAC as first line chemotherapy for patients (pts) with metastatic breast cancer (MBC). Proc Am Soc Clin Oncol 2002, 21:25a, (abstract 137).

17. Dolled-Filhart M, McCabe A, Giltnane J, Cregger M, Camp RL, Rimm DL: Quantitative in situ analysis of beta-catenin expression in breast cancer shows decreased expression is associated with poor outcome. Cancer Res 2006, 66:5487-5494.
18. McCabe A, Dolled-Filhart M, Camp RL, Rimm DL: Automated quantitative analysis (AQUA) of in situ protein expression, antibody concentration, and prognosis. J Natl Cancer Inst 2005, 97:1808-1815.

19. Moeder CB, Giltnane JM, Harigopal M, Molinaro A, Robinson A, Gelmon K, Huntsman D, Camp RL, Rimm DL, American Society of Clinical Oncology; College of American Pathologists: Quantitative justification of the change from $10 \%$ to $30 \%$ for human epidermal growth factor receptor 2 scoring in the American Society of Clinical Oncology/College of American Pathologists guidelines: tumor heterogeneity in breast cancer and its implications for tissue microarray based assessment of outcome. J Clin Oncol 2007, 25:5418-5425.

20. Frasor J, Stossi F, Danes JM, Komm B, Lyttle CR, Katzenellenbogen BS: Selective estrogen receptor modulators: discrimination of agonistic versus antagonistic activities by gene expression profiling in breast cancer cells. Cancer Res 2004, 64:1522-1533.

21. De Laurentiis M, Cancello G, D'Agostino D, Giuliano M, Giordano A, Montagna E, Lauria R, Forestieri V, Esposito A, Silvestro L, Pennacchio R, Criscitiello C, Montanino A, Limite G, Bianco AR, De Placido S: Taxanebased combinations as adjuvant chemotherapy of early breast cancer: a meta-analysis of randomized trials. J Clin Oncol 2008, 26:44-53.

22. Andre F, Mazouni C, Liedtke C, Kau SW, Frye D, Green M, GonzalezAngulo AM, Symmans WF, Hortobagyi GN, Pusztai L: HER2 expression and efficacy of preoperative paclitaxel/FAC chemotherapy in breast cancer. Breast Cancer Res Treat 2008, 108:183-190.

23. Konecny GE, Thomssen C, Luck HJ, Untch M, Wang HJ, Kuhn W, Eidtmann H, du Bois A, Olbricht S, Steinfeld D, Möbus V, von Minckwitz G, Dandekar S, Ramos L, Pauletti G, Pegram MD, Jänicke F, Slamon DJ: Her-2/ neu gene amplification and response to paclitaxel in patients with metastatic breast cancer. J Natl Cancer Inst 2004, 96:1141-1151.

24. Welsh AW, Moeder CB, Kumar S, Gershkovich P, Alarid ET, Harigopal M, Haffty BG, Rimm DL: Standardization of estrogen receptor measurement in breast cancer suggests false-negative results are a function of threshold intensity rather than percentage of positive cells. J Clin Oncol 2011, 29:2978-2984.

doi:10.1186/bcr2937

Cite this article as: Baquero et al:: Evaluation of prognostic and predictive value of microtubule associated protein tau in two independent cohorts. Breast Cancer Research 2011 13:R85.

\section{Submit your next manuscript to BioMed Central and take full advantage of:}

- Convenient online submission

- Thorough peer review

- No space constraints or color figure charges

- Immediate publication on acceptance

- Inclusion in PubMed, CAS, Scopus and Google Scholar

- Research which is freely available for redistribution

Submit your manuscript at www.biomedcentral.com/submit
Biomed Central 